\title{
Written consent for laparoscopic tubal occlusion and medico-legal implications
}

\author{
Rasiah Bharathan, Rebecca Rawesh, Hasib Ahmed
}

\begin{abstract}
Objective To analyse the completeness of written consent for laparoscopic tubal occlusion and to consider the medico-legal implications of incomplete written consent.

Methods A retrospective review was undertaken of the medical records of all women who had laparoscopic tubal occlusion in 2006 in a district general hospital to elicit details of risks of the procedure as recorded on the consent form. The extent of documentation of risks and complications that were cited in the guidelines was analysed. In addition, the grade of doctor and the timing of obtaining written consent were studied.
\end{abstract}

Results A total of 267 women underwent laparoscopic tubal occlusion and $214(80.1 \%)$ case notes were reviewed in the present study. The findings demonstrate wide variation in the description of risks by doctors of different grades. The majority of written consents (65.9\%) were obtained on the day of surgery. In most cases $(75.2 \%)$ trainees were responsible for obtaining written consent.

Conclusion Although the written consent form is a legally effective document, the process of documentation is inconsistent and this may leave the senior gynaecologist in a vulnerable position.

Keywords consent, laparoscopic tubal occlusion, medicolegal

J Fam Plann Reprod Health Care 2009; 35(3): 177-179

(Accepted 17 February 2009)

\section{Introduction}

Obtaining valid informed consent is a process that is required by the principles of good medical practice. Guidelines regarding this process have been published by a number of organisations including the General Medical Council $(\mathrm{GMC})^{1}$ and the British Medical Association (BMA). ${ }^{2}$ With certain exceptions (e.g. mental health, fertility treatment) there is no statutory requirement in the UK to obtain written consent prior to medical investigation or treatment. However, case law has established that touching a patient without valid consent may constitute the civil or criminal offence of battery. In the event of harm to the patient as a consequence of treatment, failure to obtain valid informed consent may be regarded as a factor in a claim of negligence against the health professional involved. ${ }^{3}$ A written consent form may be used in a court of law as evidence that bilateral discussion had taken place and consent obtained, but in itself is no proof of validity in obtaining that consent.

The GMC considers that "in exceptional circumstances the task of reaffirming consent can be delegated to a doctor who is suitably trained and qualified, is sufficiently familiar with the process and possesses the appropriate communication skills". 1 The BMA further clarifies this position by asserting that the responsibility of ensuring that valid informed consent has been obtained lies with the most senior clinician responsible for the investigation or treatment offered. ${ }^{2}$ The NHS Plan 4 identified the need for change in consenting practice and subsequently the Department of Health issued a consent policy and model consent forms to be used throughout the National Health Service (NHS). ${ }^{5}$ This wave of changes underpinned a core principle of good practice: using a valid informed consenting process that is patient-centred.

\section{Department of Obstetrics and Gynaecology, Medway Maritime} Hospital, Gillingham, UK

Rasiah Bharathan, MRCS, MRCOG, Specialist Registrar

Rebecca Rawesh, mBBs, Foundation Year 2

Hasib Ahmed, FRCOG, Consultant

Correspondence to: Dr Rasiah Bharathan, Department of Obstetrics and Gynaecology, Worthing Hospital, Lyndhurst Road, Worthing BN11 2DH, UK. E-mail: r.bharathan@doctors.org.uk

\section{Key message points}

- Written consent for laparoscopic tubal occlusion is inconsistent.

- The current medico-legal climate indicates that the consenting process is exposed to legislative risk.

- We propose an entity-specific booklet to strengthen the consenting process.

Obstetrics and gynaecology is one of the most litigation-prone medical specialties in the UK. 6 An important root cause of many clinical adverse events that lead to medico-legal issues is poor communication between the patient and the health care staff. ${ }^{7-9}$ Good communication regarding critical aspects of patient care should be reflected in the process of obtaining valid informed consent for diagnosis and treatment. The inadequacy of this aspect in other clinical specialties has been highlighted in recent literature. ${ }^{10-12}$

The Royal College of Obstetricians and Gynaecologists (RCOG) has published an advice document on consent for laparoscopic tubal occlusion. ${ }^{13}$ The purpose of this retrospective study was to examine the extent to which the RCOG advice has been observed at our hospital and to consider the implications of incomplete written consent.

\section{Methods}

Patients who underwent laparoscopic tubal occlusion during a 12-month period were identified by clinical coding; by this method 267 patients were found. We retrospectively reviewed the consent forms of 233 patients. In the remaining 34 cases the consent forms could not be studied for one of the following reasons: patient records were not accessible $(n=21)$ or consent forms were not attached to the patient records $(n=13)$. In those 13 cases, the pre-operative checklist confirmed that they had a written consent form. A further 19 consent forms were not included in the study as these patients had been consented for concomitant procedures. Risks and complications identified in the RCOG consent advice were studied (Table 1). A suitable proforma was devised and the data were recorded by two of the authors (RB and RR). 
Table 1 Complications as outlined by the Royal College of Obstetricians and Gynaecologists Laparoscopic Tubal Occlusion: Consent Advice $3^{13}$ recorded by doctors of differing grades

\begin{tabular}{|c|c|c|c|c|}
\hline \multirow[t]{2}{*}{ Complication } & \multicolumn{3}{|c|}{ Grade of doctor [n (\%)] } & \multirow[t]{2}{*}{$p$} \\
\hline & $\begin{array}{l}\text { Consultant } \\
(n=53)\end{array}$ & $\begin{array}{l}\text { Registrar } \\
(n=113)\end{array}$ & $\begin{array}{l}\text { Senior House Officer } \\
(n=48)\end{array}$ & \\
\hline Contraception failure & 41 (77) & $92(81)$ & $40 \quad(83)$ & 0.73 \\
\hline Ectopic pregnancy & $29(55)$ & $77(68)$ & 30 (63) & 0.24 \\
\hline Permanence & $26(49)$ & $56(50)$ & $27 \quad(56)$ & 0.70 \\
\hline Bleeding & $38(72)$ & $90(80)$ & 41 (85) & 0.23 \\
\hline Uterine perforation & $6(11)$ & $12(11)$ & $6(13)$ & 0.94 \\
\hline Conversion to laparotomy & $30(57)$ & $94(83)$ & $37 \quad(77)$ & 0.001 \\
\hline Shoulder-tip pain & $0 \quad(0)$ & 2 (2) & $0 \quad(0)$ & 0.41 \\
\hline Death & $0 \quad(0)$ & $0 \quad(0)$ & (0) & - \\
\hline
\end{tabular}

\section{Results}

In all cases 'NHS Consent Form 1' was used. 5 The median age of the patients was 38 (range, 23-46) years. Nineteen $(9 \%)$ patients were treated as inpatients for anaesthesiarelated reasons. Seventy-three $(34 \%)$ patients had completed written consent prior to the day of the procedure; in the remaining cases written consent was obtained on the day of the operation. Consultants were responsible for $53(25 \%)$ instances, registrars obtained consent from $113(53 \%)$ and senior house officers (SHOs) were responsible in the remaining 48 (22\%) cases.

From Table 1 it is apparent that amongst the consultant staff no single complication or risk of surgery is consistently documented in the consent forms. Both the consultants and the registrars commonly documented the risks of contraception failure, ectopic pregnancy, bleeding, internal organ injury and conversion to laparotomy. Internal organ injury was consistently recorded by SHOs in all cases. In the majority of the cases of consent obtained by SHOs the risk of conversion to laparotomy, bleeding, contraception failure and ectopic pregnancy were recorded. A notable feature is that in only approximately half the cases is the 'permanence' of the procedure explicitly written on the consent form by doctors of any grade. Uterine perforation was mentioned least frequently (in $11-13 \%$ of cases) on the consent forms.

Statistical analysis using the Chi-square test $(3 \times 2)$ only demonstrated significant differences between grades of staff with regard to two items in the RCOG's consent advice, namely risk of organ injury $(p=0.03)$ and risk of need for conversion to laparotomy $(p=0.001)$. Overall with regard to the advice of the RCOG on obtaining consent for laparoscopic tubal occlusion, SHOs documented the greatest number of risks or complications $(45 \%)$, followed by registrars $(42 \%)$ and consultants $(36 \%)$. The commonly encountered post-operative symptom of shoulder-tip pain was documented in only 2/214 patients. The rare complication of death was not documented on any of the consent forms we studied.

\section{Discussion}

It is evident from our data that there is wide variation in the profile of risks and complications recorded on the consent form. Provision of information is an essential aspect of ensuring valid consent. The 'Bolam test' has been used by the courts to assess whether a doctor is guilty of negligence in failing to provide an acceptable standard of care. ${ }^{14}$ If the provision of care is in line with the recommendations of a responsible body then the defendant is unlikely to be found guilty. The Bolam principle has been viewed as being excessively reliant on medical opinion supporting the defendant. However, since the case of Sidaway, several trials have shown that courts are willing to be critical of 'responsible bodies' of medical opinion. ${ }^{15}$ This case applied the Bolam principle to obtaining the consent of patients. It highlighted the need to obtain complete informed consent rather than merely 'valid' consent, which might omit certain serious rare complications. Therefore clinicians are advised to inform patients of any 'material' or 'significant' risks in the proposed treatment, any alternatives to it and the risks incurred by doing nothing. ${ }^{3}$ The GMC has taken a further step in guiding the consent process in stating that it should take account of patients' individual needs and priorities when providing information; ${ }^{1}$ this would be consistent with the principle of patient-centred processes.

The more recent case of Chester v Afshar reinforces the place of patient expectations as well as focusing on obtaining informed consent. ${ }^{16}$ Ms Chester was not informed of a $1-2 \%$ risk of cauda equina syndrome complicating a spinal procedure to which she had consented. Unfortunately the patient suffered this complication. The ruling was that the surgeon had breached his duty of care by not fully informing the patient. The critical medico-legal aspect of this ruling was that the claimant was not required to demonstrate a causal aspect of consenting in the adverse outcome she experienced. Technically the procedure was performed to a professional standard. The claimant successfully argued that the failure to inform her of this risk had influenced the timing and/or the choice of surgeon, which might in turn have affected her risk profile. In an earlier case in Australia, a court found an ophthalmic surgeon negligent for not warning a patient of a 1 in 14000 risk of blindness. ${ }^{17}$ Incomplete consenting adds weight to a claim for negligence and therefore places senior gynaecologists and their employers in a vulnerable position. The issue of inconsistency in obtaining written consent has been highlighted in other specialties; ${ }^{10-12}$ this would suggest an underlying problem in obtaining consistent written evidence of consent.

As mentioned earlier, the GMC states that only in 'exceptional circumstances' should responsibility for obtaining consent be delegated to a 'suitable' practitioner; 1 however, the most senior clinician remains responsible for the outcome of the patient. ${ }^{2}$ In this study, trainees were responsible for obtaining written consent in $75 \%$ of cases and SHOs mentioned more risks than did consultants. It is notable that the irreversible nature of tubal occlusion was recorded in only approximately half the consent forms. The rare but 'significant' complication of death was not recorded on any forms.

Patient information leaflets should supplement the clinical consultation. The RCOG, as well as the National Institute for Health and Clinical Excellence (NICE), have 
produced a number of patient leaflets on contraception. ${ }^{18,19}$ Our study only examined the risks communicated through the written consent form. It is likely that additional information may have been conveyed verbally (with documentation in the medical records) and supplemented through patient information leaflets.

We propose the use of a contraception-specific booklet that would include background information, treatment options with risks and benefits, consequences of not 'managing' contraception (i.e. risks of unwanted pregnancies) as well as a template to capture the woman's risk profile. We believe that this approach would certainly advance the clinician's position with regard to obtaining fully informed consent. Implementation of such a document across the country would confer consistency to the process of consenting. The verbal, written and psychological aspects that span the doctor-patient relationship cannot be captured and entirely quantified; the spirit in which consenting is conducted may be open to interpretation. Valid informed consent could be viewed as a compass guiding us towards the implementation of good medical practice. We believe that the medico-legal complexity of the written consent form is not accurately understood in clinical practice.

\section{Conclusions}

Written consent captured by the NHS model consent form is a legally effective adjunct in obtaining patients' consent. Our study demonstrates that our current hospital practice for obtaining written evidence of valid informed consent for laparoscopic tubal occlusion is not optimal. It is evident from recent court rulings that unless all common and significant risks of a specific treatment or its alternatives are clearly communicated to the patient, as a claimant a patient would have the opportunity to mount a case of negligence in the care we provide. This study highlights the need to implement a consenting process that is both medico-legally and clinically coherent. Our recommendation is to implement the use of an entityspecific, patient-sensitive information booklet to strengthen that process.

\section{Acknowledgement}

The authors would like to thank Dr David Crook of the NHS South East Research \& Development Support Unit (Sussex), for assistance with statistical analysis.

Statements on funding and competing interests Funding None identified.

Competing interests None identified.
References

1 General Medical Council (GMC). Consent: Patients and Doctors Making Decisions Together. June 2008. http://www.gmc-uk.org/guidance/ethical_guidance/ consent_guidance/index.asp [Accessed 14 January 2009].

2 British Medical Association (BMA). Consent Tool Kit. July 2008. http://www.bma.org.uk/images/ConsentToolKit2008_tcm41175551.pdf [Accessed 14 January 2009].

3 Department of Health. Reference Guide to Consent for Examination or Treatment. London, UK: Department of Health, April 2001.

4 Department of Health. The NHS Plan: A Plan for Investment, $A$ Plan for Reform. (Command Paper Cm 4818-I). 2000. http://www.nhs.uk/nationalplan/nhsplan.htm [Accessed 14 January 2009].

5 Department of Health. Good Practice in Consent: Achieving the NHS Plan Commitment to Patient-Centred Consent Practice (Health Service Circular HSC 2001/023). 2001. http://www.dh.gov.uk/en/Publicationsandstatistics/Lettersand circulars/Healthservicecirculars/DH_4003736 [Accessed 14 January 2009].

6 National Health Service Litigation Authority (NHSLA). NHSLA Factsheet 3: Information on Claims. November 2008. http://www.nhsla.com/home.htm [Accessed 14 January 2009].

7 Pearlman MD. Patient safety in obstetrics and gynecology: an agenda for the future. Obstet Gynecol 2006; 108: 1266-1271.

8 White AA, Pichert JW, Bledsoe SH, Irwin C, Entman SS. Cause and effect analysis of closed claims in obstetrics and gynecology. Obstet Gynecol 2005; 105(5 Pt 1): 1031-1038.

9 Argent VP. Medico-legal problems in gynaecology. Curr Obstet Gynaecol 2006; 16: 289-294.

10 Chadha NK, Pratap R, Narula A. Consent process in common nose and throat procedures. J Laryngol Otol 2003; 117: 536-539.

11 Edwards AG, Weale AR, Morgan JD. Informed consent in renal transplantation. Postgrad Med J 2005; 81(953): 188-190.

12 Chen AM, Leff DR, Simpson J, Chadwick SJD, McDonald PJ. Variation in consenting practice for laparoscopic cholecystectomy. Ann R Coll Surg Engl 2006; 88: 482-485.

13 Royal College of Obstetricians and Gynaecologists. Laparoscopic Tubal Occlusion: Consent Advice 3. 2004. http://www.rcog.org.uk/files/rcog-corp/uploaded-files/ Consent3Laparoscopictubal2004.pdf [Accessed 14 January 2009].

14 Bolam v Friern Hospital Management Committee [1957] 1 WLR 582.

15 Sidaway $\vee$ Board of Governors of Bethlam Royal Hospital [1985] AC 871.

16 Chester v Afshar [2004] 4 All ER 587 (HL).

17 Rogers v Whitaker [1992] 67 AWR 47.

18 Royal College of Obstetricians and Gynaecologists (RCOG). Sterilisation for Women and Men: What You Need to Know. http://www.rcog.org.uk/womens-health/clinical-guidance/ sterilisation-women-and-men-what-you-need-know [Accessed 14 January 2009].

19 National Institute for Health and Clinical Excellence (NICE). Long-acting Reversible Contraception. October 2005. http://guidance.nice.org.uk/CG30 [Accessed 14 January 2009].
Picking Up the Pieces: A Survival Guide for Victims of Childhood Sexual Abuse. Graham Wilmer, Eve Wilmer, Aidan Hughes, Rory Wilmer. Wallasey, UK: The Lantern Project, 2008. ISBN-13: 978-0-9558750-0-7. Price: £8.50. Pages: 112 (paperback)

Just occasionally, a book comes along that stands head and shoulders above the pack. Picking $U p$ the Pieces is one of those books.

If, like me, your work covers childhood sexual abuse, you know that there is always a need for follow-up resources (or indeed for resources aimed at helping the client take those first painful steps to even facing the issues).

Materials need to be informative yet empathetic; it's a difficult line to tread, steering clear of over-objectivity whilst at the same time not falling into the trap of trivial sentimentality. This book treads that line, and surely one of the reasons it does so is that it is written by a sexual abuse survivor, Graham Wilmer, with help from fellow survivors. As a result, every word is written directly from experience of suffering and coming through the trauma of abuse.

The book falls into two parts. Part One contains clear, practical self-help: what child sexual abuse is, how it impacts through adult life, whether to tell or not, how to begin to resolve the issues, coping with mental health problems. There are specific sections written (by a woman) for female survivors and (by a man) for male survivors. A further legal section is equally helpful (though it presumably runs the risk of becoming outdated; hopefully the book will have regular reprints)

Part Two contains a series of pieces - prose and verse - reflecting the experiences, thoughts and feelings of survivors. These range from a few moving sentences about loss of innocence through to several pages telling the story of a number of abused men. All the pieces, short or long, have the same ring of wounded desperation, but also of great resilience and hope. The result, whilst unbearably moving, is to send the message - from survivors themselves - that there is a way through the pain to healing.

The book, at just over 100 pages long, is written in wonderfully plain English and is also beautifully illustrated and produced. In short, it is a guide that would surely help any survivor, or their loved ones, and I will certainly be recommending it to suitable clients.

[NB. The book is published by The Lantern Project (www.lanternproject.org.uk), a charity started by Graham Wilmer to help abuse survivors; the website too seems a useful resource to recommend.]

Reviewed by Susan Quilliam, BA, MNLP Freelance Writer, Broadcaster and Agony Aunt, Cambridge, UK 